\title{
Trabalhonecessário
}

Issn: 1808 - 799X

ano 14 , número $23-2016$

\section{Prefácio de Nicos Poulantzas ao livro A Internacional Comunista e a escola de classe ${ }^{1}$}

Apresentamos aos leitores da Trabalho Necessário um pequeno texto de Nicos Poulantzas escrito, a título de Prefácio, para o livro A internacional comunista e a escola de classe, de autoria de Daniel Lindenberg, cuja tradução para a língua portuguesa foi publicada pela Editora Centelha, de Coimbra, Portugal, no ano de 1977. A obra, pouco conhecida, tanto em Portugal quanto no Brasil, e hoje raramente encontrada, reúne um conjunto de textos "produzidos por organismos membros ou simpatizantes da terceira Internacional (1919-1943)" (Lindenberg, 1977, p.17). Organizada com o objetivo de estabelecer um diálogo com a França de 1968, nela o autor afirma considerar fundamental "mostrar que Maio de 68 e, em geral, a revolta mundial da juventude escolar, não implica a revisão nem mesmo o abandono puro e simples do marxismo-leninismo como arma de compreensão-transformação da realidade" (Idem, p.16).

A antologia, além de oferecer ricas introduções a cada grupo de produções selecionadas, apresenta, inicialmente, textos curtos derivados da Segunda Internacional para, em seguida, debruçar-se sobre seu foco central. São, então, reunidos textos soviéticos, contemplando o período de 1917 a 1932, textos alemães de 1919 a 1929 e, finalmente, textos franceses produzidos entre os anos de 1929 e 1931.

Para o cuidadoso trabalho do Professor de Ciência Política da Universidade Paris VIII, que, no decorrer dos anos de 1970, se dedicou ao estudo da história das ideias, Nicos Poulantzas, cujo pensamente influenciou fortemente Lindenberg, elaborou um prefácio em que apresenta importantes reflexões sobre a questão educacional, em particular, em sua forma escolar. Nele, o intelectual marxista grego aborda fecundos conceitos que enriquecem a reflexão acerca da educação, como

\footnotetext{
${ }^{1}$ LINDENBERG, Daniela. A Internacional Comunista e a escola de classe. Coimbra: Centelha, 1977
} 


\section{Trabalhonecessário}

Issn: 1808 - 799X

ano 14, número $23-2016$

qualificação-sujeição e centrismo-escolar. Ressalta, também, que o papel dos Aparelhos Ideológicos do Estado - nomenclatura que trás a marca de Althusser, forte influência em Poulantzas - só pode ser plenamente compreendido se considerarmos o papel que desempenham "na própria constituição de um modo de produção das relações sociais" (Poulantzas, 1977, p. 08, In: Lindenberg, 1977).

Ao sublinhar a importância atribuída à educação e à cultura no âmbito da Internacional Comunista, o autor grego ressalta que a questão escolar, na época, era revestida de grande atualidade e da uma "importância política decisiva". Não é outro o cenário que hoje se descortina no Brasil, haja vista a intensa disputa que a classe dominante vem travando no âmbito da escola pública, visando a avançar sobre ela em todas as esferas administrativas e político-pedagógicas, com o intuito de exercer controle férreo sobre os mecanismos de "qualificação-sujeição" destinados à classe trabalhadora. 


\section{Trabalhonecessário}

Issn: 1808 - 799X

ano 14 , número $23-2016$

COLEÇÃO: Temas/Centelha - Educação

TÍTULO: A internaiconal comunista e a experiência de classe

AUTOR: Daniel Lindinberg

CAPISTA: João Botelho

EDITOR: CENTELHA - Promoção do Livro, SARL - apartado 241 Coimbra

\section{Prefácio}

Este volume sobre a Internacional Comunista e a Escola de classe é o primeiro de uma série que terá por fim essencial apresentar textos do movimento operário, em particular da terceira Internacional, que permitam esclarecer objectivos estratégicos de importância na actual conjuntura.

A publicação desses textos parece-nos responder, a vários títulos, a uma necessidade real.

Com efeito, a crise que o imperialismo atravessa actualmente, por um lado, a acuidade da luta de classes que a acompanha e por outro, a cisão no movimento 


\section{Trabalhonecessário}

Issn: 1808 - 799X

ano 14 , número $23-2016$

comunista mundial, fez surgir uma série de questões e de problemas relativos à estratégia e aos objectivos do operário. Ora, estas questões e problemas têm, na maior parte dos casos, marcado igualmente os debates e a luta travados pela terceira Internacional. E se acredita que o passado pode servir de lição para o presente e para o futuro, estes textos são de uma grande actualidade para os problemas que se põem aqui e agora.

Os debates acerca dessa questão existiram. Nada mais falso do que considerar, tal como uma tradição solidamente estabelecida refere, que a terceira Internacional foi essencialmente caracterizada por vazios, espaços em brancos, fossos e silêncios teórico-políticos. Através de suas relações com o movimento operário mundial, a Internacional Comunista sistematizou, com efeito, durante longo tempo, sob uma forma explícita e coerente, a ideologia proletária e a teoria marxistaleninista sobre toda uma série de questões que se considera muitas vezes actualmente como tendo sido deixadas até aqui pelo movimento de massas ou, quando muito, como tendo sido apenas sob forma espontânea ou instintiva. E se é verdade que as ideias correctas vêm das massas, toda elaboração teórica destas questões não pode deixar de referir-se a esta experiência histórica, que determina largamente a conjuntura actual.

Dito isto, a experiência da terceira Internacional apresenta limites, limites que se referem ao mesmo tempo no período no qual ele se situa e à linha política geral que, através de diversas alterações aí prevaleceu: é o que as análises de D. Lindenberg destacam bem no domínio particular da questão escolar.

Estes textos da Internacional Comunista foram objecto, durante anos, de uma ocultação prodigiosa; e particularmente em França. Em relação a isto é curioso constatar, por exemplo, a sua actual reedição na Alemanha, na Itália, na GrãBretanha e o silêncio que se continua a verificar à volta deles em França, apesar de algumas tentativas meritórias, mas raras e isoladas. 


\section{Trabalhonecessário}

Issn: 1808 - 799X

ano 14 , número $23-2016$

As razões gerais desta ocultação são suficientemente conhecidas para voltarmos a elas. Mas, no que respeita a França, refira-se apenas a dificuldade característica que a implantação do Marxismo aí encontrou, para além das aparências, nomeadamente entre os intelectuais. Dizer que a inteligência francesa progressista e de esquerda de todos os azimutes foi durante longo tempo influenciada por um idealismo congénito, do qual ainda se notam as sequelas, parece apenas um exagero. A hegemonia ideológica, longo tempo incontestada da burguesia francesa, na sua variante pequeno-burguesa radical, humanista, republicana e jacobina é uma das causas disso.

Se começarmos esta série com um volume sobre a questão escolar, não se deve concluir daí que partilhamos certos pontos de vista actualmente muito difundidos sobre a escola e que lhes conferem um privilégio muitas vezes abusivo. Com efeito:

1) Não está provado que a escola seja 0 aparelho ideológico dominante do modo de produção capitalista. Nomeadamente Gramsci, que foi o primeiro a explicar a concepção dos aparelhos ideológicos do Estado, pensava que esse papel cabia ao aparelho sindical de colaboração de classe. Mais ainda: podese avançar que o Estado do M.P.C ${ }^{2}$, e por razões complexas relacionadas simultaneamente com relações de produção deste modo na sua articulação com o político e ideológico e com formas específicas que aí revestem as classes e as lutas de classes, não possui, com efeito, como tal, um aparelho dominante invariável. $\mathrm{E}$ isto tal como no caso do aparelho relegioso no modo de produção feudal em que, como notava Marx, o papel determinante das relações de produção se reflectia no papel dominante da ideologia sob a sua

\footnotetext{
2 M.P.C - modo de produção capitalista.
} 


\section{Trabalhonecessário}

Issn: 1808 - 799X

ano 14, número $23-2016$

forma religiosa. No caso do M.P.C, o papel dominante entre os A.I.E $E^{3}$ pode ser assumido por aparelhos ideológicos diferentes - portanto, também pela escola - segundo os estádios deste modo na sua combinação concreta no interior de cada formação social capitalista, e a luta de classes que aí se desenrola, numa palavra, segundo as etapas históricas que cada formação capitalista atravessa. São justamente essas etapas que determinam as formas de reprodução da ideologia dominante e, nomeadamente, as formas do seu domínio sobre a formação da força de trabalho, portanto a qualificação-sujeição, em sentido lato, dos agentes. Este desvio de domínio no seio dos aparelhos ideológicos do Estado, conjugado com os desvios de domínio deste ou daquele ramo do aparelho repressivo do Estado - exército, administração, polícia, magistratura - modifica as relações entre o aparelho repressivo, por um lado, e os aparelhos ideológicos, por outro, e implica assim uma reorganização do conjunto do sistema político, marcando as diferenças entre formas de Estados e formas de regime capitalistas; diferenças devidas às formas concretas da luta de classes - configuração concreta do bloco no poder, desvios da hegemonia de uma classe ou fração para uma outra mudança das relações de força no seio desse bloco, formas de alianças e papel das classes-apoio, luta da classe operária e das massas populares, ação das forças e categorias sociais, crises políticas, etc..

2) A escola - e os outros aparelhos não criam a divisão em classes, mas contribuem para essa divisão e, por consequência, para a sua reprodução alargada. Há que destacar ainda todas as aplicaçãoes da afirmação acima referida: que não são só as relações de produção que determinam os aparelhos de Estado que presidem à luta de classes, como defende toda a tradição institucionalista, mas a luta de classes, a todos os níveis, que comanda os aparelhos.

\footnotetext{
${ }^{3}$ A.I.E - aparelhos ideológicos do Estado.
} 


\section{Trabalhonecessário}

Issn: 1808 - 799X

ano 14 , número $23-2016$

Com efeito, é preciso atribuir a maior importância ao papel exacto dos aparelhos ideológicos na produção, nomeadamente a reprodução da força de trabalho e dos meios de trabalho. Isto é uma consequência de facto de que são às relações de produção, na sua relação constitutiva quanto às relações de domínio/subordinação política e ideológica, que dominam o processo de trabalho no seio do processo de produção.

Esta reprodução alargada das classes sociais (relações sociais), comporta dois aspectos que apenas existem na sua unidade:

a) A reprodução alargada dos lugares que os agentes ocupam. Entre lugares designam a determinação estrutural das classes, isto é, o modo de existência da determinação pela estrutura - relações de produção, domínio/subordinação política e ideológica - nas práticas de classe (as classes não existem senão na luta de classes): o que assume o aspecto de um efeito de estrutura sobre a divisão social do trabalho. Esta determinação das classes, que só existe assim como luta de classes, mas que se deve distinguir da posição de classe na conjuntura, rege, aliás, a sua reprodução: por outras palavras, e Marx, é preciso dizê-lo, sublinhava-o, é a própria existência de um modo de produção abrangendo a burguesia e o proletarido que leva à reprodução alargada da burguesia e do proletariado.

b) A reprodução-distribuição dos próprios agentes pelos lugares.

Este segundo aspecto da reprodução que põe o problema: quem, como e em que momento ocupa este ou aquele lugar - é ou torna-se burguês, camponês pobre, etc. - está subordinado ao primeiro, quer dizer, à reprodução dos próprios lugares das classes sociais (ao facto de o capitalismo, na sua reprodução alargada reproduzir a burguesia, o proletariado, a pequena-burguesia sob nova forma na fase actual do capitalismo monpolista, etc.) ou ainda eliminar tendencialmente certas classes e fracções de classe no seio das formações sociais onde tem lugar a sua 


\section{Trabalhonecessário}

Issn: 1808 - 799X

ano 14 , número $23-2016$

reprodução alargada - e os camponeses parcelares, a pequena burguesia tradicional, etc.). Por outras palavras, se é verdade que os próprios agentes devem ser reproduzidos - qualificados-sujeitos - para ocupar certos lugares, não é menos verdade que esta distribuição dos agentes não atende às suas escolhas ou aspirações, mas à própria reprodução desses lugares.

É importante assinalar já que a distinção entre esses dois aspectos da reprodução, a dos lugares e a dos agentes, não evidencia a distinção entre reprodução das relações sociais, por um lado, reprodução da força de trabalho, por outro. Estes dois aspectos marcam o conjunto da reprodução, no interior do qual domina a reprodução das relações sociais de que estamos a tratar. Mas, no conjunto da reprodução, incluindo a das relações sociais, é a reprodução dos lugares que constitui o aspecto principal.

Ora, o papel dos aparelhos do Estado, incluindo a escola como aparelho ideológico, não é o mesmo quanto a estes dois aspectos da reprodução.

É certo que a determinação estrutural das classes, não sendo limitada a lugares no único processo de produção - a uma situação económica das classes em si mas estendendo-se a todos os graus da divisão social do trabalho, estes aparelhos intervêm como marcação das relações ideológicas e políticas - do domínio ideológico e político - na determinação das classes. Estes aparelhos intervêm assim, pelo papel que desempenham na reprodução das relações políticas e ideológicas, na reprodução dos lugares que definem as classes sociais. Refira-se, portanto, de passagem, que o papel da superestrutura não se limita, como por vezes se sustenta, à simples reprodução, tal como o papel da base não se limita apenas à produção e reprodução dos produtos e dos meios do trabalho (mas estende-se à reprodução das relações sociais); o papel dos aparelhos na reprodução não pode ser explicado, como acontece para toda a reprodução, senão pelo papel que 


\section{Trabalhonecessário}

Issn: 1808 - 799X

ano 14, número $23-2016$

desempenha na própria constituição de um modo de produção (e de suas relações de produção) isto é, pelo seu papel na própria produção das relações sociais.

Os A.I.E , intervêm, portanto, activamente na reprodução dos papeis das classes sociais. Mas, a menos que se caia numa visão idealista e institucionalista das relações sociais, que apresenta as classes sociais e a luta de classes como o produto dos aparelhos, é preciso ver que este aspecto da reprodução ultrapassa os aparelhos e escapa-Ihes largamente, estabelecendo-lhes os seus limites. Pode-se, com efeito, falar de uma primeira reprodução - de uma reprodução fundamental das classes sociais na e através da luta de classes, onde se joga a reprodução alargada da estrutura, incluindo relações de produção - e que preside ao funcionamento e ao papel dos aparelhos. Para considerar um exemplo deliberadamente esquemático: não é a existência de uma escola que forme proletários e novos pequenos-burgueses que determina a existência da reprodução - extensão, diminuição, certas formas de categorização, etc. - da classe operária e nova pequena-burguesia: pelo contrário, a acção das relações de produção das formas complexas da propriedade económica e do controle sobre o processo de trabalho, ou seja, o processo de produção na sua articulação com as relações políticas e ideológicas e deste modo, a luta - económica, política e ideológica - das classes que tem como efeito esta escola. Isto explica porque razão a reprodução através dos aparelhos não se faz sem lutas, contradições e fricções constantes no seu seio. Ao fim e ao cabo, é desta maneira que se pode compreender a outra face da questão: tal como a reprodução alargada das relações sociais depende da luta de classes, a sua revolucionarização depende igualmente dessa luta.

Esta reprodução fundamental das classes socias não diz respeito apenas às posições nas relações de produção, ou seja, às relações sociais de produção. Não se trata de uma auto-reprodução económica das classes face a uma reprodução ideológica e política unicamente através dos aparelhos. Trata-se assim de uma primeira reprodução dentro e através da luta de classes, em todos os graus da 


\section{Trabalhonecessário}

Issn: 1808 - 799X

ano 14 , número $23-2016$

divisão social do trabalho. Tal como a sua determinação estrutural, esta reprodução das classes sociais diz respeito igualmente às relações (sociais) políticas e às relações (sociais) ideológicas da divisão social do trabalho que, na relação com as relações sociais de produção, revestem um papel decisivo. É porque a divisão social do trabalho, ela prórpria, não diz respeito apenas às relações políticas e ideológicas, mas também às relações sociais de produção, no seio das quais domina a divisão técnica do trabalho: o que é uma consequência do domínio das relações de produção sobre o processo de trabalho no seio de um processo de produção.

Dizer que esta primeira reprodução das situações das classes sociais depende da luta de classes é dizer também que as suas formas concretas dependem da história da formação social: tal ou tal reprodução da burguesia e da classe operária, das classes do campesinato da antiga e da nova pequenaburguesia a forma e o ritmo específico de reprodução, em França, da pequeno burguesia tradicional e do campesinato médio, sob o capitalismo, atendendo às formas específicas de sua aliança, durante longo tempo, com a burguesia. O papel dos aparelhos nesta reprodução apenas pode portanto ele próprio ser situado em relação a esta luta: este respeito, o papel especial da escola em França apenas pode ser situado claramente com relação à aliança burguesia-pequena burguesia que durante muito tempo marcou a formação social francesa.

Quer isto dizer que se a reprodução alargada das situações das classes sociais faz apelo, nomeadamente no campo ideológico-político, aos A.I.E., ela não se limita a isso.

Consideremos o caso da divisão entre trabalho manual e trabalho intelectual: esta divisão, própria para a determinação dos lugares na divisão social do trabalho, não se limita de modo nenhum apenas ao domínio económico onde, diga-se de passagem, ela não tem, intrinsecamente, papel próprio quanto à divisão das classes - o trabalhador produtivo, o proletário que produz mais-valia / mercadorias não 


\section{Trabalhonecessário}

Issn: 1808 - 799X

ano 14, número $23-2016$

realiza de modo nenhum apenas trabalho manual. A divisão trabalho manual / trabalho intelectual não pode ser concebida senão abrangendo as relações políticas e as relações ideológicas ao mesmo tempo da divisão social do trabalho na empresa - autoridade e direcção do trabalho ligadas ao trabalho intelectual e ao segredo do saber - e do conjunto da divisão social do trabalho, relações que intervêm na determinação dos lugares das classes sociais. Mas, é claro que não é a escola, ou outros aparelhos ideológicos que criam esta divisão, ou que são os principais e únicos factores da sua reprodução, aparecendo aí ao mesmo tempo sob a sua forma capitalista, como efeito dessa divisão e de sua reprodução na e através da luta de classes. Por outras palavras, se a escola reproduz no seu próprio seio a divisão entre o trabalho manual e o trabalho intelectual, é porque essa escola está já, pela sua natureza capitalista, situada globalmente em relação a - e reproduzindo como aparelho em função de - uma divisão trabalho manual / trabalho intelectual - e uma reprodução desta divisão - que ultrapassa a escola e lhe indica o seu papel (separação da escola e da produção, ligada à separação e à expropriação do produtor directo dos meios de produção).

Mas mais: é preciso ver, visto que se fala de aparelhos ideológicos, que estes aparelhos, tal como não criam a ideologia, não são os principais ou os únicos factores da relação da reprodução das relações de domínio / subordinação ideológica. Os aparelhos ideológicos não fazem senão elaborar e inculcar a ideologia dominante: não é a Igreja, que como M. Weber defendia, cria e perpetua e Igreja. Quanto às relações ideológicas capitalistas, as análises de Marx referentes ao fetichismo da mercadoria, que se relaciona precisamente com processo de valorização do capital, oferecem um excelente exemplo de uma reprodução da ideologia dominante que ultrapassa os aparelhos: o que, aliás, Marx notava, ao falar muitas vezes de uma correspondência, que implica uma distinção das instituições e das formas de consciências sociais. Numa palavra, o papel da ideologia e do político 


\section{Trabalhonecessário}

Issn: 1808 - 799X

ano 14, número $23-2016$

na reprodução alargada dos lugares das classes sociais reencontra aqui directamente a luta de classes que comanda os aparelhos.

Por fim, como consequência do que fica dito, a reprodução dos lugares nas relações de domínio ideológico e político, por muito que faça apelo aos aparelhos, faz igualmente apelo a outros aparelhos para além dos A.I.E., nomedadamente ao próprio aparelho económico. Uma empresa, enquanto unidade de produção sob a sua forma capitallista, constitui igualmente um aparelho no sentido de que ela própria reproduz, através da divisão social do trabalho no seu seio - organização despótica do trabalho - as relações políticas e ideológicas no que se refere ao papel das classes sociais. Por outras palavras, a reprodução das relações ideológicas, que tem um papel capital, não é somente exclusivo dos aparelhos ideológicos, como se tudo o que se passasse na produção apenas dissesse respeito ao económico, reservando-se os aparelhos ideológicos o monopólio da reprodução das relações de domínio ideológico.

Vejamos agora o segundo aspecto da reprodução, a reprodução dos agentes. Esta reprodução engloba, como momentos de um mesmo processo, a qualificaçãosujeição dos agentes de tal maneira que eles possam ocupar os lugares, e a distribuição dos agentes por esses lugares: é compreendendo exactamente a articulação dos dois aspectos da reprodução, a dos lugares e a dos agentes, que se pode compreender a inutilidade da problemática buguesa da mobilidade social. Ora os A.I.E. e nomeadamente a escola, têm aqui uma função particular e portanto decisiva. Embora haja que fazer certas observações:

1) É verdade que a reprodução dos agentes, nomeadamente a famosa qualificação dos agentes da própria reprodução, não consiste apenas numa simples divisão técnica do trabalho - uma formação técnica -, mas constitui-se uma efectiva qualificação-sujeição, estendendo-se às relações políticas e ideológicas: com efeito, esta reprodução alargada dos agentes assume aqui um aspecto da reprodução das 


\section{Trabalhonecessário}

Issn: 1808 - 799X

ano 14, número $23-2016$

relações sociais que imprime as suas características à reprodução da força de trabalho no processo de trabalho. Ora, se isso implica um papel particular, quanto a isto, da escola, é preciso não esquecer que esta qualificação-sujeição tem lugar como tal - e não só como formação técnica à pressão - tal como no seio do prórpio aparelho económico a empresa não constitui uma simples unidade de produção. Isto determina, aliás, o papel próprio da empresa, como aparelho precisamente, na distribuição dos agentes no seu seio. Este papel do aparelho económico é mesmo dominante quanto aos trabalhadores imigrados, mas não diz respeito só a eles. Esquecer este papel do aparelho económico, e apresentar os agentes como desde logo exaustivamente distribuídos na escola - antes do aparelho económico - seria cair no mesmo tipo de explicação regressiva e unívoca que considera estes agentes como desde logo exaustivamente distribuídos na família - antes da escola. As classes capitalistas, tal como não são castas de origem ou de hereditariedade, não são também castas escolares. Tal como finalmente, esta explicação regressiva não vale para a relação família-escola, na medida em que a família continua a exercer a sua acção durante a escola, ela não vale para a relação escola-aparelho económico, continuando a escola a exercer a sua actividade durante a activdade económica dos agentes: a isso chama-se pudicamente educação permanente.

2) É preciso ver que este aspecto da reprodução está subordinado ao primeiro - é porque, e na medida em que, há reprodução alargada dos lugares, que há esta ou aquela reprodução - distribuição dos agentes por eles - e está-lhe indissoluvelmente ligado. E seria bom não esquecer aqui que o papel determinante quanto à distribuição dos agentes no conjunto da formação social volta ao mercado de trabalho, como expressão da reprodução alargada das relações de produção: $e$ isso mesmo que não se trate propriamente de um mercado de trabalho unificado, ou seja, mesmo que o mercado do trabalho exerça a sua procura num campo já compartimentado, devido, entre outras razões, à acção própria dos A.I.E. (não é um 


\section{Trabalhonecessário}

Issn: 1808 - 799X

ano 14, número $23-2016$

estudante-desempregado que irá preencher o lugar vago de um O.E. ${ }^{4}$ ) É porque existe, igualmente, no aspecto de distribuição, uma relação constitutiva entre aparelhos distribuidores e relações de produção expressas no mercado de trabalho: relação que, entre outras coisas, impõe os limites da acção dos A.I.E. nesta compartimentação do mercado de trabalho. Não é, por exemplo, a escola que faz com que sejam principalmente camponeses que ocupem os lugares suplementares dos operários. É o êxodo dos campos, ou seja, a eliminação dos postos de trabalho nos campos que acompanha a reprodução alargada da classe operária, que rege o papel da escola nesta matéria.

3) Por fim, na medida em que este aspecto da reprodução está subordinado ao primeiro, e em que se trata da reprodução alargada, é preciso limitar os efeitos directos dos próprios lugares sobre os agentes, o que não é outra coisa senão considerar aqui o primado da luta de classes sobre os aparelhos. Com efeito, não se trata propriamente de agentes orignalmente (pré-ou extra escolarmente) livres e móveis, circulando entre esses lugares segundo as injunções dos aparelhos ideológicos e segundo a inculcação ideológica ou a formação que recebem. É verdade que as classes do M.P.C. e de uma formação social capitalista não são castas, que a origem dos agentes não os liga a lugares determinados, e que o papel próprio dos distribuidores da escola e dos outros aparelhos dos agentes entre estes lugares é muito importante. Mas, não é menos verdade que estes efeitos de distribuição se manifestam pelo facto de, através dos aparelhos ideológicos, serem precisamente os burgueses que continuam - e os seus filhos se tornam massivamente burguses, e que são os proletários que continuam - e os seus filhos se tornam massivamente proletários. Isto mostra que não é nem principalmente, nem exclusivamente devido à escola que a distribuição assume esta forma, mas devido aos efeitos dos próprios lugares sobre os agentes, efeitos que ultrapassam a escola, e, aliás, a própria família. Não se trata precisamente, neste caso, como

\footnotetext{
${ }^{4}$ O.E . - operário especializado
} 


\section{Trabalhonecessário}

Issn: 1808 - 799X

ano 14, número $23-2016$

certos debates actuais puderam fazer supôr, de uma alternativa família-escola na ordem de causalidade; não se trata mesmo de um acasalamento família-escola como principal fundados destes efeitos de distribuição. Trata-se antes de uma série de relações entre aparelhos que mergulha as suas raízes na luta de classes. Por outras palavras, trata-se de uma primeira distribuição dos agentes ligados à principal reprodução dos lugares das classes sociais: é ela que assinala a este ou àquele aparelho, ou a esta ou àquela série de entre eles, e seguindo as etapas e as fases da formação social, o respectivo papel conveniente que eles assumem na distribuição dos agentes.

\section{III}

Embora seja necessário precaver-se contra um centrismo-escolar típico entre professores e alunos, o certo é que não é menos verdade que a questão escolar é uma questão actual de uma importância política decisiva: é o que significa a escolha deste primeiro volume. A obra de D. Lindenberg preenche aqui uma lacuna importante e constitui uma peça indispensável das análises marxistas actuais sobre a escola. Os textos que ele apresenta mostram bem que a questão escolar não foi negligenciada pelo movimento comunista. Surgiu imediatamente uma luta encarniçada, aberta, organizada da terceira Internacional contra a escola capitalista. Lutas fundadas em análises que muitas vezes foram bastante longe: ver-se-á, por exemplo, nestes textos que a ideia segundo a qual a Escola única - a famosa democratização da escola - é impossível sob o capitalismo é um lugar comum das análises marxistas da época; ver-se-á igualmente que a revolução ideológica ou revolução cultural esteve presente nos debates dos comunistas europeus relativos à escola. Foi uma luta dramática, da qual D. Lindenberg mostra bem, através dos documentos, as voltas, as peripécias, os sucessos e os reveses, até no próprio seio da União Soviética. 


\section{Trabalhonecessário}

Issn: 1808 - 799X

ano 14 , número $23-2016$

A política da Internacional Comunista referente à questão escolar articula-se, nos seus traços gerais, com as grandes etapas e alterações da política de Komintern: não me detenho nesse aspecto, tendo tentado analisar esse problema em Fascismo e Ditadura. A terceira Internacional frente ao fascismo. Notar-se-á, todavia, como o demonstra bem D. Lindenberg, que esta articulação não impede um desenvolvimento orginal desta linha geral, segundo os domínios sobre os quais incide. Por fim, notar-se-ão as desigualdades na aplicação da linha geral de Komintern, que vão até uma autêntica elaboração de linhas originais, segundo os diversos países, a situação concreta que os especifica, e os traços originais de seus respectivos Partidos comunistas: nada mais claro a esse respeito, quanto à questão escolar, como as diferenças entre a Alemanha e a França. 